\title{
INVASIVE SPECIES IMPACT: DIRECT AND INDIRECT INTERACTIONS BETWEEN TWO STREAM SNAILS AND THEIR Algal ReSOURCES
}

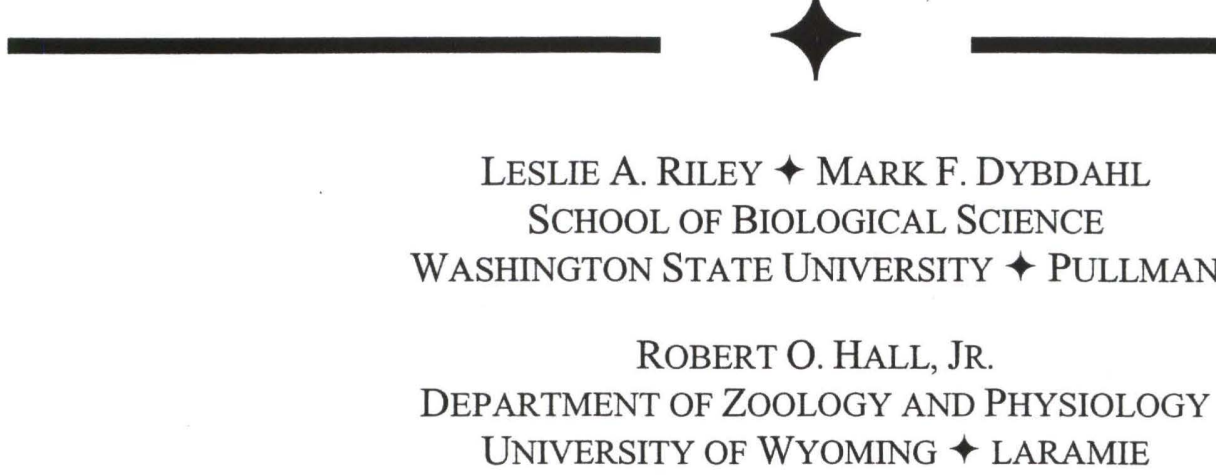

\section{$\downarrow$ ABSTRACT}

We measured the strength of direct and indirect interactions in order to develop a standardized estimate of the impact of an invasive snail on its resource and a competitor. The freshwater New Zealand snail, Potamopyrgus antipodarum, an invasive species in the western U.S., is the most abundant benthic macroinvertebrate grazer in several rivers, where it overlaps with several threatened endemic snails. In one watershed, Potamopyrgus coexists with the snail, Pyrgulopsis robusta, which may be affected by resource competition with Potamopyrgus. In field enclosure experiments, we quantified the direct grazing effect of snails on algae and the indirect effects between consumers. Potamopyrgus significantly limited growth of Pyrgulopsis. In contrast, Pyrgulopsis appeared to facilitate growth of the invasive snail (Potamopyrgus). In natural populations, snail densities were positively correlated over five sites, but negatively correlated at two downstream sites. Interaction strengths between snails and algae were equivalent for both snails at both sites, indicating that invasion success could not be attributed to differences in resource acquisition. However, the overall impact of the invader was much higher at the downstream site when both snail abundance and interaction strengths were considered. Negative
\end{abstract}

individual effects of Potamopyrgus at two trophic levels in conjunction with high Potamopyrgus abundance demonstrated a significant impact of the invader in this lotic community.

\section{$\downarrow \quad$ INTRODUCTION}

Invasive species are the second leading cause of the biodiversity crisis (Wilcove et al. 1998). Introduced into ecosystems where they have not evolved, invaders can successfully establish and threaten native biota, depending on the role they assume in a community (Vitousek 1990). While much debate has focused on general factors that control invasion success (e.g. Simberloff 1981; Keane and Crawley 2002; Torchin et al. 2003), general aspects of invasive species impacts are still unknown (Strayer 1999). Parker et al. (1999) proposed that impact could be related to the combination of three components: range, abundance and per unit effect. Of these components, per unit or individual effects are important because invasive species might have a large impact if they interact strongly in the invaded community, especially if they also are abundant. Dissecting the strength of direct and indirect interactions in a community interaction network might provide an appropriate framework to help standardize invasive species impact. 
Competition for resources with native biota occupying the same trophic level has been cited with increasing frequency as a way that exotics might impact native communities (e.g. Petren and Case 1996; Juliano 1998; Byers 2000). The strength of the direct interactions of introduced and native species can be measured as the amount of resource depletion. If one or both species are having large direct effects on a resource, i.e. high interaction strengths, then negative indirect effects via exploitative competition between native and invader will likely be present (Morin 1999). Competition can be predicted by these direct interactions, and quantified by measuring the indirect interaction strengths between the two consumers. If such direct and indirect effects are strongly negative, then it indicates the potential for resource competition ultimately to displace native species (Petren and Case 1996; Byers 1999) and alter community structure (Vitousek et al. 1996). By measuring per unit biomass interaction strengths of direct and indirect interactions, estimates of population-level impacts can be calculated by multiplying by biomass (Wootton 1997; Parker et al. 1999).

We were interested in the competitive impact in the western United States of the New Zealand mud snail (Potamopyrgus antipodarum), a worldwide invader. Resource competition has been commonly studied among aquatic gastropods (e.g. Hawkins and Furnish 1987; Schmitt 1996; Cross and Benke 2002) and can be particularly important in shaping freshwater stream communities (Kohler and Wiley 1997). Potamopyrgus (a prosobranch gastropod) was first recorded in the western US in 1987, and now has a widespread, but patchy distribution, including several areas of conservation significance (i.e. Yellowstone, Grand Teton and Grand Canyon National Parks). Many narrowly endemic prosobranch snails are listed as threatened or endangered in the intermountain west (Hershler 1998) where the New Zealand mud snail now resides. For example, the genus Pyrgulopsis contains many narrowly endemic species in the Great Basin region, including two recently extinct species (Hershler 1998). Pyrgulopsis robusta, a candidate-threatened endemic species in one stream (Polecat Creek), has decreased in yearly samples since Potamopyrgus appeared (Gustafson, pers. comm.) but remains abundant in a small tributary of this stream. Densities of Potamopyrgus have reached 500,000 snails $/ \mathrm{m}^{2}$ in some areas of Polecat Creek (Hall et al. 2003). Potamopyrgus and Pyrgulopsis occupy similar habitats (vegetation and cobble areas within geothermally influenced streams), potentially consume the same algal resources (periphyton and algal detritus) (Haynes and Taylor 1984) and are taxonomically related (Class Prosobranchia, Family Hydrobiidae).

Our study investigated direct consumerresource interactions and indirect interactions between two resource-sharing consumers to test the prediction that Potamopyrugus is competing with Pyrgulopsis for algal resources. In the first year of the study (2001), we assessed 1) the effect of each snail species on the growth of the other using a competition experiment, and 2) the correlation of snail densities along a transect including Polecat Creek and a tributary stream. In the second year, we tested for spatial variation in competitive effects by repeating the competition experiment at two sites. At both sites, we estimated 3) the direct impact of snails on the growth of the resource (periphytic algae) by measuring interaction strengths (Wootton 1997; Laska and Wootton 1998). Finally, we assessed 4) interaction strengths of each snail species on the other to quantify this indirect interaction (Paine 1992). We found that Potamopyrgus has a negative indirect effect on Pyrgulopsis, and that Pyrgulopsis has a positive indirect effect on Potamopyrgus, suggesting facilitation of the invader by the native.

\section{METHODS}

Study sites

Our study sites were two streams within the Snake River watershed (Polecat Creek and an unnamed tributary spring stream, hereafter referred to as Marmot Spring) on the South Boundary of Yellowstone National Park in Wyoming, USA. Polecat Creek is a geothermally-influenced spring stream where Potamopyrgus reaches high densities $\left(250,000-500,000\right.$ individuals $\left./ \mathrm{m}^{2}\right)$ but Pyrgulopsis is currently absent in this reach of the stream. In contrast, the two species coexist in Marmot Spring, where both occupy cobbles, logs, macrophytes and macroalgae.

\section{Field survey}

We sampled seven sites along Marmot Spring (1-5) and Polecat Creek (6 and 7) in the summer of 2001 (Fig. 1). We gathered five replicate core samples, collected with a stovepipe $\left(0.018 \mathrm{~m}^{2}\right)$ in macrophytes at each site. We preserved the samples in $10 \%$ formalin solution and counted snail densities in the laboratory, converting to biomass using length-mass regressions (described below). 


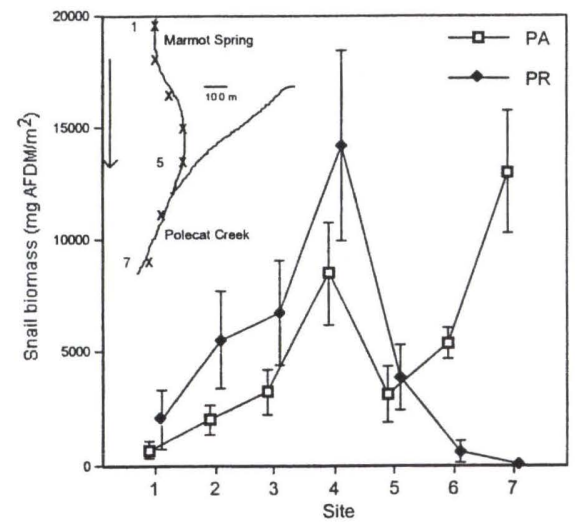

Fig. 1. Biomass of Potamopyrgus (PA) and Pyrgulopsis (PR) in Marmot Spring and Polecat Creek. Sites $1-5$ correspond to spring stream sites with site 1 being the farthest upstream. Sites 6 and 7 correspond to sites in Polecat Creek. Error bars are \pm 1 standard error. Snail biomass is calculated as $\mathrm{mg} \mathrm{AFDM} / \mathrm{m}^{2}$. The upper left corner shows a schematic depicting sampling regime for 2001. "X"s are sampling sites with the arrow indicating the direction of water flow.

\section{Competition}

To examine competition between Potamopyrgus and Pyrgulopsis in 2001, we measured snail growth of each species at various levels of snail abundance in cage enclosures in the stream. To examine intraspecific competition for each species, we used three levels of snail biomass (664, 1660, $\left.2880 \mathrm{mg} \mathrm{AFDM} / \mathrm{m}^{2}\right)$ that are multiples $(2 \mathrm{x}, 5 \mathrm{x}$, and $9 \mathrm{x}$ ) of a low value of ambient biomass (1x or $332 \mathrm{mg}$ $\mathrm{AFDM} / \mathrm{m}^{2}$ ). Hence, experimental biomass levels represent the lower end of the ambient range.

To assess the effects of interspecific competition, we assembled cages that contained both species, holding one species at the $1 \mathrm{x}$ biomass level (target species) and adding the other species (competitor) at biomass levels of $1 \mathrm{x}, 4 \mathrm{x}$ or $8 \mathrm{x}$. The target species were held at a $1 \mathrm{x}$ biomass (27 Potamopyrgus or 15 Pyrgulopsis) to minimize intraspecific competition among target snails. The total biomass in each interspecific treatment regime matched the total biomass of the intraspecific treatments, allowing comparisons between the two modes of competition.

To measure snail growth in the 2001 experiment, we painted 15 individuals from each cage. Marked individuals were measured weekly with calipers and then returned to cages. At the end of the experiment, marked snails were measured and preserved in $10 \%$ formalin solution. Weekly length measurements of Pyrgulopsis and Potamopyrgus were converted to snail biomass (mg AFDM) using length/mass regressions for each species (Hall unpublished data, Riley unpublished data). The specific growth rate $\mathrm{g}$ (1/day) was calculated as:

$$
g=\frac{\left(\ln M_{t}-\ln M_{0}\right)}{t}
$$

where $\mathrm{M}_{\mathrm{t}}$ is the biomass of a snail at the conclusion of the experiment, $\mathrm{M}_{0}$ is the initial biomass of a snail and $t$ is the duration of the experiment (d).

We repeated the competition experiment during summer 2002 with four modifications. First, in addition to Marmot Spring, we performed studies at a downstream Polecat Creek site where Potamopyrgus abundance is extremely high and Pyrgulopsis abundance is extremely low (Fig. 1). Second, we increased the high snail biomass treatment and used two levels of biomass, $2 \mathrm{x}$ (664 $\left.\mathrm{mg} \mathrm{AFDM} / \mathrm{m}^{2}\right)$ and $15 \mathrm{x}$ (4980 $\left.\mathrm{mg} \mathrm{AFDM} / \mathrm{m}^{2}\right)$. Third, the fifteen target snails were not paint-marked, but instead were distinguished by shorter shell lengths than non-target snails in the cages. Finally, we reduced the duration of the experiment from four weeks to two weeks, which provided sufficient time for measurable snail growth.

To test for statistical differences in snail growth from the 2001 experiment, a two-way ANOVA used total snail biomass in each treatment and mode of competition (intraspecific or interspecific) as fixed factors. In 2002, a three-way ANOVA was used, with site, snail biomass and mode of competition (intraspecific or interspecific) as fixed factors. Each species was analyzed separately with the statistical package NCSS (NCSS 2000).

\section{Interaction strengths}

\section{Consumer-resource interactions}

The direct interaction between consumer and resource may drive the indirect interaction between two consumers. Therefore, during summer 2002, we performed a separate field enclosure experiment to measure differences in the interaction strength between each snail species and the algal periphyton by quantifying the reduction in algal biomass due to the presence of Pyrgulopsis and Potamopyrgus over one week.

Variation in competitive effects could be attributed to a difference in direct snail grazing effects between Marmot Spring and Polecat Creek. 
To compare snail-algae interaction strengths between sites, we created three treatments at each site: $15 \mathrm{x}$ Potamopyrgus, 15x Pyrgulopsis and 0x, or no snails. After one week, we measured chlorophyll $a$ on rocks as an indicator of algal biomass (APHA 1989). This experiment was conducted twice at each site in two consecutive weeks. We analyzed the effect of each treatment on chlorophyll $a$, using treatment, site and block (week) as factors in a three-way ANOVA (NCSS 2000).

Algal reduction by each species was measured as the difference between algal biomass at $15 \mathrm{x}$ snail biomass compared to the no snail treatment. We calculated interaction strengths from the following equation, adapted from Wootton (1997):

$$
\frac{\ln \left(\frac{N_{t}, s>0}{N_{t}, s=0}\right)}{S t}=-c
$$

where $N_{t}, s>0$ is the concentration of chlorophyll a ( $\mu \mathrm{g}$ chlorophyll $\mathrm{a} / \mathrm{cm}^{2}$ ) with snails present, $\mathrm{N}_{\mathrm{t}}, \mathrm{s}=0$ is chlorophyll a ( $\mu$ g chlorophyll $\mathrm{a} / \mathrm{cm}^{2}$ ) with snails absent, $\mathrm{S}$ is snail biomass (mg AFDM) for $\mathrm{N}_{\mathrm{t}}, \mathrm{s}>0, t$ is time (days) and $-c$ is per biomass interaction strength $\left(\left(\mathrm{mg} \quad \mathrm{AFDM} / \mathrm{m}^{2}\right)^{-1} \mathrm{~d}^{-1}\right)$. More negative values indicate the snail species that lowers algal biomass to a greater extent per unit of snail biomass per unit of time. This dynamic index of interaction strength, or log-response ratio, is derived from the discrete-time version of Lotka-Volterra equations (Berlow et al. 1999) and provides a useful empirical estimate that can be compared across species. In addition, the dynamic index does not assume equilibrium conditions and works well for short-term experiments (Laska and Wootton 1998; Berlow et al. 1999; Berlow et al. 2004).

We used a bootstrap procedure to calculate interaction strengths that imitated the experimental set-up (e.g. Paine 1992). We chose values of $N_{t}, s>0$ and $\mathrm{N}_{\mathrm{t}}, \mathrm{s}=0$ at random with replacement for individual cages for each species. The interaction strength was then calculated from these values. This process was repeated 1000 times for each species and standard errors were generated preserving the number of replicates in the original design. We then determined if resampling distributions differed significantly from zero by calculating the number of times our estimate was greater than or equal to zero for 1000 bootstrap runs (Good 2001, Resampling Stats 2000).

\section{Consumer-consumer interactions}

We also quantified the indirect interaction between consumers by calculating the strength of snail-snail interactions. We used a different measure of interaction strength based on underlying assumptions of these empirical estimates. A dynamic index measures the effect of snails on algae in a short-term experiment, where we can assume algal densities are far from equilibrium (Laska and Wootton 1998; Berlow et al. 1999). However, in longer - term competition experiments, the Paine index is best suited to measure interactions between snails. Thus, the use of two indices most appropriately estimated interaction strengths under different timescales (Berlow et al. 1999).

Unlike estimates for direct consumerresource interactions above, these values could be extrapolated to population impacts only if individual growth rates were directly correlated with reproduction and fitness (i.e. population growth rate). However, calculating interaction strengths between two consumers can indicate whether competition (negative values) or facilitation (positive values) is occurring. These values were estimated from the 2002 competition experiments so interaction strengths could be compared between snail species and sites (i.e. 2001 experiment only included Marmot Spring). Consumer-consumer interaction strengths were calculated using the following equation (Laska and Wootton 1998, based on Paine 1992),

$$
\frac{\ln \left(\frac{E}{C}\right)}{M}=\alpha
$$

where $\mathrm{E}$ is the specific growth rate $(\mathrm{g})$ of the target snail with competitors present, $\mathrm{C}$ is the specific growth rate $(\mathrm{g})$ of the target snail with competitors absent, $\mathrm{M}$ is the biomass of the competitor (mg $\mathrm{AFDM} / \mathrm{m}^{2}$ ) and $\alpha$ is per biomass effect of the competitor on growth of the target snail, or interaction strength $\left(\left(\mathrm{mg} \mathrm{AFDM} / \mathrm{m}^{2}\right)^{-1}\right)$.

We again used a bootstrap procedure to calculate these competition interaction strengths. Growth rates of target snails in control cages $(2 x$ intraspecific treatment) and experimental cages (15x treatments) were chosen at random and with replacement. Competition interaction strengths were calculated on Resampling Stats as described above (Resampling Stats 2000). 


\section{$\downarrow \quad$ RESULTS}

Field survey

Pyrgulopsis dominated total snail density in Marmot Spring, while Potamopyrgus dominated in Polecat Creek. Densities of the two species were positively correlated when examining all Marmot Spring sites (r = 0.96) (Fig. 1). Additionally, Pyrgulopsis biomass was higher at all of these sites (Fig. 1). We observed the opposite trend in Polecat Creek where the biomass of Potamopyrgus was up to 600 times greater than that of Pyrgulopsis (Fig. 1).

\section{Competition}

Under competition, snail growth rates should decrease with increasing snail biomass, indicating negative density dependence, regardless of the mode of competition (intraspecific vs. interspecific). Instead, Potamopyrgus grew faster at higher levels of intraspecific competition $(9 x)$ in 2001 (Fig. 2a; $\mathrm{p}=0.039$ ). In 2002, growth rates of Potamopyrgus were 1.5 times lower in $15 \mathrm{x}$ than in $2 \mathrm{x}$ treatments in both Marmot Spring and Polecat Creek (Figs. 2b, 2c; p<0.001).
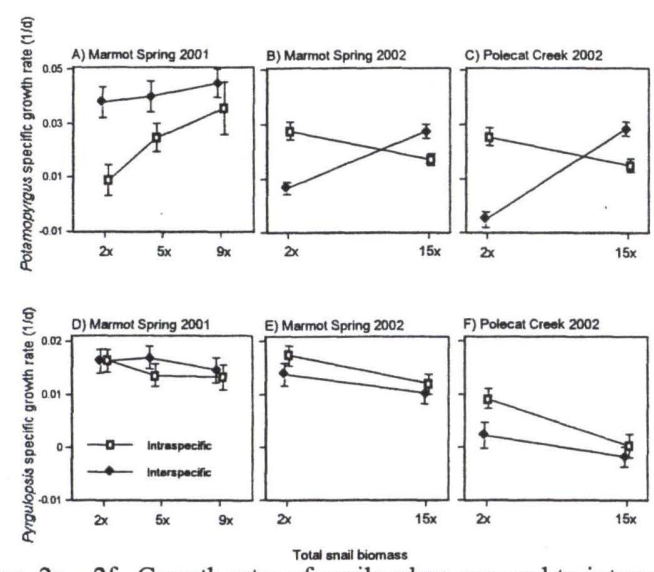

Figs. $2 a-2$ f. Growth rates of snails when exposed to intraspecific and interspecific competition in 2001 and 2002. Figs. 2a - 2c represent Potamopyrgus growth rates. Figs. 2d - 2f show Pyrgulopsis growth rates. Error bars as in Fig.1. Intraspecific treatments only contain the target species at a biomass of $2 x, 5 x$, $9 \mathrm{x}$, or $15 \mathrm{x}$. Interspecific treatments contain a $1 \mathrm{x}$ biomass of the target species as well as the other species at a biomass of $1 \mathrm{x}, 4 \mathrm{x}, 8 \mathrm{x}$ or $14 \mathrm{x}$. The $\mathrm{x}$-axis refers to the total snail biomass within each treatment. The $y$-axis indicates the change in biomass per day.

The growth rate of Potamopyrgus under interspecific competition with the native snail was generally higher than growth rates under intraspecific competition. High Potamopyrgus growth rates did not change significantly at Pyrgulopsis densities up to $9 \mathrm{x}$ in 2001 (Fig. 2a). However, in 2002, Potamopyrgus growth rates were four times higher at the highest levels of interspecific competition $(15 \mathrm{x})$ at both sites (Figs. 2b, 2c; p<0.001). Snail biomass and mode of competition interacted, indicating that Potamopyrgus growth increased in treatments with a high density of Pyrgulopsis, but decreased when competing with a high density of conspecifics (Figs. 2b, 2c; $<<0.001)$. Potamopyrgus always grew faster when competing with the native species, compared to competition with conspecifics, at densities higher than $2 \mathrm{x}$, regardless of year, site or biomass treatment (Figs. 2a, 2b, 2c).

Patterns of intraspecific competition in Pyrgulopsis differed across years between the high biomass experimental treatments. Growth rate of Pyrgulopsis did not change when competing with increasing biomass of conspecifics up to 9x (Fig. 2d; $\mathrm{p}=0.578$ ). In contrast, Pyrgulopsis displayed negative density dependence in 2002 at $15 x$ (Figs. 2e, 2f; p<0.001).

Unlike Potamopyrgus, Pyrgulopsis growth rates declined under interspecific competition. Growth of Pyrgulopsis did not change when exposed to increasing levels of competitor biomass, up to $9 \mathrm{x}$, in 2001 (Fig. 2d; $\mathrm{p}=0.578$ ). However, in the $15 \mathrm{x}$ snail biomass treatments in 2002, Potamopyrgus reduced growth rates of Pyrgulopsis to levels $2-9$ times lower than $2 \mathrm{x}$ intraspecific competition treatments (Figs. 2e, 2f; $\mathrm{p}<0.001$ ). Pyrgulopsis growth rates were at least five times slower under interspecific competition in Polecat Creek, compared to Marmot Spring (Figs. 2e, 2f).

\section{Interaction strengths}

\section{Consumer-resource interactions}

Consumer-resource interaction strengths were negative but consistent between species and sites. Increasing snail density lowered algal biomass (Figs. 3a, 3b; $<<0.001$ ) and there was no difference in the amount consumed by each species, as indicated by a Bonferroni test for multiple comparisons $(\mathrm{p}<0.05)$. The invasive and native snails had almost identical interaction strengths (Figs. 3c, 3d), although the interaction strengths varied between blocks (Figs. 3c, 3d). Higher chlorophyll concentrations in block A in Marmot Spring indicates the standing stock of periphytic algae was greater during the first week (Figs. 3a, 3b), but did not affect the direction or magnitude of the interaction. 

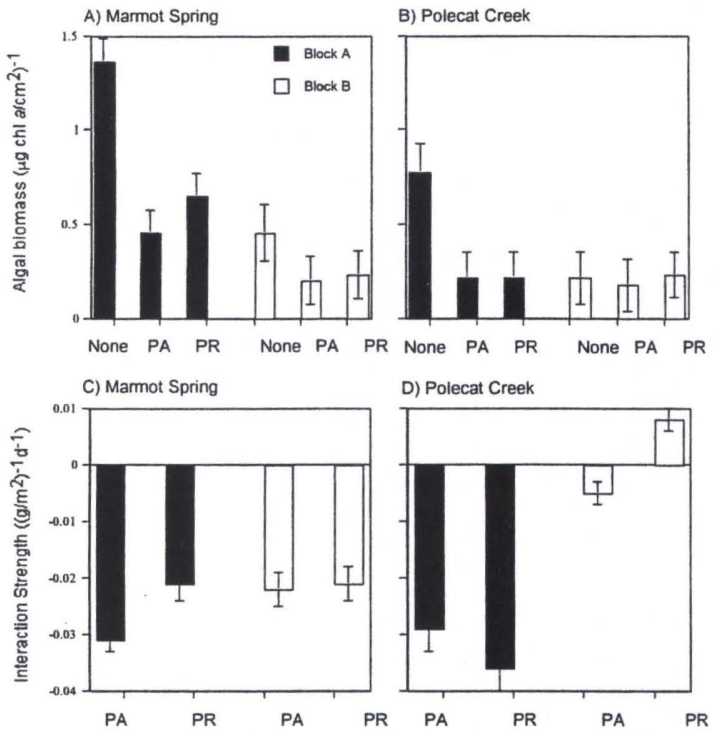

Figs. 3a - 3d. Snail grazing and interaction strengths with periphytic algae over one-week periods in 2002. Figs. 3a and $3 \mathrm{~b}$ depict snail grazing effects. "None" indicates treatments with no snails, "PA" indicates treatments with Potamopyrgus at a $15 \mathrm{x}$ biomass and "PR" indicates treatments with Pyrgulopsis at a $15 \mathrm{x}$ biomass. Error bars as in Fig. 1. "A" and "B" are replicate experiments performed one week apart. Figs. $3 \mathrm{c}$ and $3 \mathrm{~d}$ are bootstrapped interaction strengths $\left(\left(\mathrm{g} / \mathrm{m}^{2}\right)^{-1} \mathrm{~d}^{-1} \pm 1\right.$ s.e $)$ calculated from grazing experiments in $3 \mathrm{a}$ and $3 \mathrm{~b}$. All interaction strengths differ significantly from zero $(\mathrm{p}=0.05)$ except for block $\mathrm{B}$ in Polecat Creek.

We also expected snails to consume algae faster in Polecat Creek if competition was stronger at this site. Although total algal standing stock was two times higher in Marmot Spring compared to Polecat Creek (Figs. 3a, 3b), interaction strengths were similar at both sites during block $\mathrm{A}$ of the experiment (Figs. 3c, 3d). In addition, there was no site $\mathrm{x}$ treatment interaction, suggesting that grazing did not differ between sites and species.

\section{Consumer-consumer interactions}

Consumer-consumer interactions from the 2002 resource competition experiments showed that when Potamopyrgus was the competitor, interaction strengths were negative for both Potamopyrgus and Pyrgulopsis, indicating competition. Potamopyrgus was the stronger competitor in all situations, as indicated by negative interactions with both Pyrgulopsis and conspecifics at both sites (Figs. 4a, 4b). On the other hand, when Pyrgulopsis was the competitor, Pyrgulopsis never significantly lowered the growth rate of the invasive snail. Pyrgulopsis, instead, facilitated the growth of Potamopyrgus in Polecat Creek with a slight positive per biomass effect (Fig. 4b, $\mathrm{p}=0.06$ ).

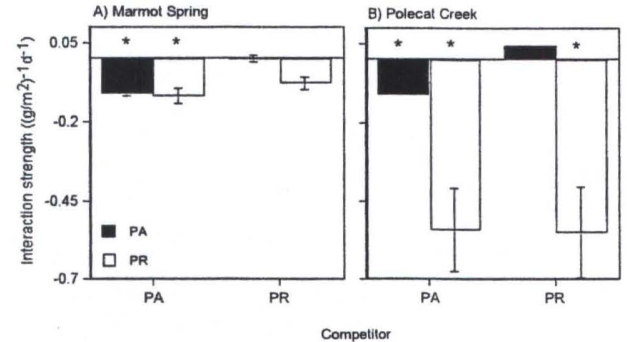

Figs. $4 \mathrm{a}$ and $4 \mathrm{~b}$. Bootstrapped interaction strengths between snails $\left(\left(\mathrm{g} / \mathrm{m}^{2}\right)^{-1} \mathrm{~d}^{-1}\right) \pm 1$ s.e. $)$ calculated from snail growth rates in 2002 resource competition experiments. Positive values indicate increased growth rates in the presence of competitors while negative values show decreased growth rates. "PA" indicates Potamopyrgus while "PR" represents Pyrgulopsis. The legend indicates the target species. Asterisks $(*)$ indicate values significantly different from zero $(\mathrm{p}=0.05)$. Standard error bars for Potamopyrgus as the target in Polecat Creek are not displayed because values are too low $(0.001)$.

\section{DISCUSSION}

We studied the impact of an invasive species in the context of an interaction web by testing the strength of direct and indirect effects between invasive (Potamopyrgus) and native (Pyrgulopsis) snails and a shared resource. Our results suggest that both competition and facilitation are affecting these species within the range of the narrowly endemic Pyrgulopsis. The direct effect of both species on algal biomass was similar and negative at both sites, as represented by consumer-resource interaction strengths. However, indirect effects were asymmetrical. Pyrgulopsis growth rates were lowest when competing with the invader, especially at high densities. In contrast, Potamopyrgus always had faster growth rates that were highest in treatments with Pyrgulopsis, suggesting that Pyrgulopsis facilitated growth of the invasive snail.

Based on the natural history of these taxonomically related, herbivorous snails, we expected competition for algal resources. We showed that, in the short-term, both species reduce algal biomass by similar amounts. The similarity is surprising because one might expect successful invasion by Potamopyrgus to occur because (1) the resource acquisition rate of the invader was higher (e.g. Petren and Case 1996) or (2) resource levels were not reduced to a great extent by the native resulting in resource opportunities for the invader (reviewed in Shea and Chesson 2002). In both scenarios, the grazing effect of the invader should be much larger than the native snail. However, despite similar per unit effects on the resource by the two 
species, Potamopyrgus still appeared to be a superior competitor because it grew faster than Pyrgulopsis under all treatments and slowed growth of the native snail during interspecific competition. This outcome suggests that Potamopyrgus has lower maintenance costs, or may be more efficient at converting resources to growth, as has been suggested for another invasive snail (Byers 2000).

Although direct interactions with the resource were similar, indirect consumer-consumer interactions appeared to be asymmetrical. In Pyrgulopsis, growth rates were slower in interspecific competition treatments with Potamopyrgus compared to intraspecific treatments. This outcome, indicating that the native species was negatively affected by the invasive competitor, was expected given the decrease in algal resource caused by the invader. These competitive effects on Pyrgulopsis occurred at low to moderate Potamopyrgus densities in natural habitats. However, Potamopyrgus growth rates either did not change (up to $9 x$ in 2001) or increased (15x in 2002) in treatments with higher biomass levels of the native species. Thus, the native snail facilitated the invasive species, and the invasive snail had a negative competitive effect on the native snail.

The occurrence of negative direct interactions with asymmetrical indirect interactions is possible because the available resource pool is likely to be heterogeneous. While overall algal biomass was measured in these experiments, the periphyton consists of taxonomically and functionally diverse algae. If these consumers display some degree of resource specialization, the direction of actual indirect effects can differ from predicted effects (Morin 1999) in two possible ways. First, the two snail species might have specialized resource requirements, consuming different forms of algae that themselves compete. If Pyrgulopsis consumed the dominant algae, it might have allowed the less dominant resource used by Potamopyrgus to thrive. A positive effect on Potamopyrgus growth would result, with no effect on the growth of Pyrgulopsis. Dethier and Duggins (1984) described this "indirect commensalism" as dictating the outcome of interspecific interactions between marine chitons and limpets. However, this scenario is inconsistent with the negative indirect effect of Potamopyrgus on Pyrgulopsis. A second explanation is that Potamopyrgus might be competitively dominant for a shared preferred algal resource, and Pyrgulopsis consumed a lower quality resource causing slower growth rates (Fig. 2). It is possible that Pyrgulopsis then removed the lower quality resource, creating space for the preferred algae to grow and indirectly facilitating the growth of Potamopyrgus (Fig. 2). This special case of an indirect commensalism has also been proposed to explain positive and negative interactions between snails and tadpoles when competing for algal resources (Bronmark et al. 1991).

Measures of direct and indirect effects as interaction strengths can be used in standardized estimates of the overall impact of an invasive species. Parker et al. (1999) proposed a framework where per unit effect of an invader, measured as the interaction strength, can be translated into impact within a given range by multiplying by population abundance.

$$
\mathrm{I} \propto \mathrm{A} \times \mathrm{E}
$$

where I is total impact of the invasive species, A is abundance and $\mathrm{E}$ is per unit effect (e.g. per unit biomass effect) (see also Ricciardi 2003). Our measures of direct and indirect effects can be used to estimate the impact on components from two trophic levels: on resources (consumer-resource interaction strengths) and another consumer (consumerconsumer interaction strengths). In addition, standardized interaction strengths also permit a comparison of effects among sites. For example, the estimated impact (A x E) of Potamopyrgus on algae (using abundance levels from the sites of the experiments) was -0.07 per day in Marmot Spring and -0.6 per day in Polecat Creek. While interaction strengths were equivalent between sites, the overall impact was ten-fold greater in Polecat Creek where Potamopyrgus occurs at biomass levels higher than Pyrgulopsis (Fig. 1), and up to $36,000 \mathrm{mg}$ AFDM $/ \mathrm{m}^{2}$ (Hall et al. 2003).

Our approach has shown the potential for the invasive Potamopyrgus to impact a narrowly endemic candidate-threatened species of snail, Pyrgulopsis, and the native community. High densities of Potamopyrgus reduced algal standing stocks, and lowered Pyrgulopsis growth. The overall impact on Pyrgulopsis and potentially on other herbivores in the native community should be magnified by the greater abundance of Potamopyrgus in Polecat Creek. Consistent with these trends, the two species coexisted in the field populations of Marmot Spring, but Potamopyrgus was more abundant in Polecat Creek. Taken together, these results might explain the distribution of these two snails if the impacts of Potamopyrgus translate into reduced fitness and displacement of Pyrgulopsis. 


\section{ACKNOWLEDGMENTS}

We thank B. Davitt, S. Fahrney, J. Folwell, D. Gustafson, L. Harvey, S. Kane, S. Pfister, J. Schaefer and M. Vanderloop for field and lab assistance. H. Harlow at the University of Wyoming/National Park Service Research Station provided field accommodations and logistical support. Helpful comments on this manuscript were provided by John G. Bishop and C. Eric Hellquist. Funding was provided by the University of Wyoming/National Park Service Research Station, NSF EPSCoR (ROH) and NSF DEB 9907373 and 0296049 (MFD).

\section{LITERATURE CITED}

APHA. (1989). Standard methods for the examination of water and wastewater. Port City Press: Baltimore, Maryland.

Berlow EL, SA Navarrete, CJ Briggs, ME Power and BA Menge. (1999). Quantifying variation in the strengths of species interactions. Ecology 80: 2206-2224.

Berlow EL, NM Neutel, JE Cohen, PC De Ruiter, B Ebenman, M Emmerson, JW Fox, VAA Jansen, JI Jones, GD Kokkoris, DO Logofet, AJ McKane, JM Montoya and O Petchey. (2004). Interaction strengths in food webs: issues and opportunities. Journal of Animal Ecology 73: 585 - 598 .

Bronmark C, SD Rundle and A Erlandsson (1991) Interactions between freshwater snails and tadpoles: competition and facilitation. Oecologia 87:8-18.

Byers JE. (1999). The distribution of an introduced mollusc and its role in the long-term demise of a native confamilial species. Biological Invasions 1: 339-352.

Byers JE. (2000). Competition between two estuarine snails: implications for invasions of exotic species. Ecology 81: 1225-1239.

Cross WF and AC Benke. (2002). Intra- and interspecific competition among coexisting lotic snails. Oikos 96: 251-264.
Dethier MN and DO Duggins. (1984). An "indirect commensalism" between marine herbivores and the importance of competitive hierarchies. The American Naturalist 124: 205-219.

Good PI. (2001). Resampling methods: a practical guide to data analysis. Birkhauser: Boston, M. A.

Hall RO, JL Tank and MF Dybdahl. (2003). Exotic snails dominate nitrogen and carbon cycling in a highly productive stream. Frontiers in Ecology and the Environment 1: 407-411.

Hawkins CP and JK Furnish. (1987). Are snails important competitors in stream ecosystems? Oikos 49: 209-220.

Haynes A and BJR Taylor. (1984). Food finding and food preference in Potamopyrgus jenkinsi Gastropoda Prosobranchia. Archiv fuer Hydrobiologie 100: 479-492.

Hershler R. (1998). A systematic review of the hydrobiid snails (Gastropoda: Rissooidea) of the Great Basin, western United States. Part I. Genus Pyrgulopsis. Veliger 41: 1-132.

Juliano SA. (1998). Species introduction and replacement among mosquitoes: interspecific resource competition or apparent competition? Ecology 79: 255-268.

Keane RM and MJ Crawley. (2002). Exotic plant invasions and the enemy release hypothesis. Trends in Ecology and Evolution 17: 164170.

Kohler SL and MJ Wiley. (1997). Pathogen outbreaks reveal large-scale effects of competition in stream communities. Ecology 78: $2164-2176$.

Laska MS and JT Wootton. (1998). Theoretical concepts and empirical approaches to measuring interaction strengths. Ecology 79: 461-476.

Morin PJ. (1999). Community Ecology. Blackwell Science Inc., Malden, Massachusetts.

NCSS. (2000). NCSS-PASS. NCSS Statistical Software, Kaysville, Utah, USA. 
Paine RT. (1992). Food-web analysis through field measurement of per capita interaction strength. Nature 355: 73-75.

Parker IM, D Simberloff, WM Lonsdale, K Goodell, M Wonham, PM Kareiva, MH Williamson, B Von Holle, PB Moyle, JE Byers and L Goldwasser. (1999). Impact: toward a framework for understanding the ecological effects of invaders. Biological Invasions 1: 3-19.

Petren K and TJ Case. (1996). An experimental demonstration of exploitation competition in an ongoing invasion. Ecology 77: 118-132.

Resampling Stats. (2000). Resampling Stats for Windows. Resampling Stats, Inc., Arlington, Virginia, USA.

Ricciardi A. (2003). Predicting the impacts of an introduced species from its invasion history: an empirical approach applied to zebra mussel invasions. Freshwater Biology 48: 972-981.

Schmitt RJ. (1996). Exploitation competition in mobile grazers: trade-offs in use of a limited resource. Ecology 77: 408-425.

Shea K and P Chesson. (2002). Community ecology theory as a framework for biological invasions. Trends in Ecology and Evolution 17 (4): 171-176.

Simberloff D. (1981). Community effects of introduced species. Pages 53-81 in T. H. Nitecki, ed. Biotic crises in ecological and evolutionary time. Academic Press, York.
Strayer DL. (1999). Effects of alien species on freshwater mollusks in North America. Journal of the North American Benthological Society 18: 74-98.

Torchin ME, Lafferty KD, Dobson AP, McKenzie VJ and AM Kuris. (2003). Introduced species and their missing parasites. Nature 421: 628630 .

Vitousek PM. (1990). Biological invasions and ecosystem processes: towards an integration of population biology and ecosystem studies. Oikos 57: 7 - 13 .

Vitousek PM, D“Antonio CM, Loope LL and R Westbrooks. (1996). Biological invasions as global environmental change. American Scientist 84: 468-479.

Wilcove DS, Rothstein D, Dubow J, Phillips A and E Losos. (1998). Quantifying threats to imperiled species in the United States. Bioscience 48: 607-615.

Wootton JT. (1994). Predicting direct and indirect effects - an integrated approach using experiments and path analysis. Ecology 75 (1): $151-165$.

Wootton JT. (1997). Estimate and tests of per capita interaction strength: diet, abundance, and impact of intertidally foraging birds. Ecological Monographs 67: 45-64. 